\title{
Stratified Jet Flames in a Heated (1364 K) Cross-Flow with Auto-ignition
}

\author{
Daniel J. Micka ${ }^{1}$ and James F. Driscoll ${ }^{2}$ \\ Department of Aerospace Engineering, University of Michigan
}

\begin{abstract}
PLIF imaging is used to identify the internal structure of a partially-premixed lifted turbulent jet flame within a cross-flow of air that is heated to a temperature of $1364 \mathrm{~K}$, which is above the autoignition temperature. Large aerodynamic strain rates were imposed since the velocity of the cross-flow air is $480 \mathrm{~m} / \mathrm{s}$. A jet flame-in-a-cross-flow is a simple unit physics problem for which scaling relation are known for the non-reacting case. However, the present work addresses the roles of two factors: autoignition chemistry and large aerodynamic strain rates. This unit physics problem is important in propulsion devices, including ramjets and in internal combustion engines. Formaldehyde PLIF is used identify the distributed auto-ignition regions, while $\mathrm{CH}$ and $\mathrm{OH}$ PLIF identifies the (downstream) primary reaction regions.
\end{abstract}

The primary reactions are shown by the $\mathrm{CH}$ images to have the structure of broken and thickened flamelets under these high-strain rate conditions. That is, the $\mathrm{CH}$ occurs within a 2-3 mm thick wrinkled interface that is not continuous but contains many holes due to local extinction. The formaldehyde PLIF images show that there is a broad $10 \mathrm{~mm}$ thick region of formaldehyde upstream of the primary thickened flamelets. This broad formaldehyde region indicates that distributed (non-flamelet) reactions occur early in the chemical reaction process due to auto-ignition. Therefore we classify this combustion to be an "auto-ignition-assisted flame”. The measured profiles of heat release rate are presented, which are useful in assessing modeling efforts.

\section{Introduction}

The role of auto-ignition can become important when a fuel jet is injected into an air stream that has a temperature that is above the auto-ignition temperature; two basic geometries are that of a jet in a co-flow and a jet in a cross-flow. Auto-ignition chemistry is known to be important in ramjets, scramjets as well as diesel and HCCI engines. It can cause the chemical reactions that are associated with fuel breakdown into intermediates, such as formaldehyde, to be distributed over a fairly broad region in space. Significant

${ }_{1}^{1}$ currently Engineer, Creare Inc. Hanover, NH 03755, Member, AIAA

${ }^{2}$ Professor of Aerospace Engineering, University of Michigan, Fellow, AIAA 
broadening of the reaction zones can be enhanced if the convection velocities are large. Auto-ignition presents special challenges to the modeling of turbulent combustion [1, 2]. At locations where distributed reactions occur, flamelet modeling assumptions will break down. One solution is to develop a multi-zone model, such as a distributed auto-ignition zone (which includes formaldehyde reactions, for example) that is followed by a primary reaction zone that may consists of flamelets [2]. Measured images of the flame structure are needed to determine the size and structure of the distributed auto-ignition zones, as well as the primary reaction zones.

Some recent efforts have begun to investigate the role of auto-ignition for two cases: a fuel jet injected into a heated cross-flow [1, 3-6] and a fuel jet injected into a heated co-flow [7-11]. This latter geometry has been called a Cabra burner. Since the flames are lifted in these examples, the fuel and air have time to mix and form a stratified premixed mixture ahead of the reaction zone. The resulting autoignition causes the reaction zone structure to differ from that of a conventional flame in unheated air. There have been many previous investigations of conventional flames in unheated cross-flows [12-18] because the jet-in-a-cross flow is a fundamental "unit physics” problem. Hasselbrink and Mungal [10] found that they could collapse their data into a set of generalized scaling relations by using the momentum ratio (q) which is defined to be $\left(\rho_{\mathrm{F}} \mathrm{U}_{\mathrm{F}}^{2}\right) /\left(\rho_{\mathrm{A}} \mathrm{U}_{\mathrm{A}}{ }^{2}\right) ; \rho$ and $\mathrm{U}$ are gas density and velocity, and subscripts $\mathrm{F}$ and $\mathrm{A}$ denote properties of the fuel jet and air cross flow.

When the cross-flow of air is highly heated, Ben-Yakar, Mungal and Hanson [2, 3] used OH PLIF to image the $\mathrm{OH}$ regions within hydrogen and ethylene jet flames within a shock tube. Two of their images appear in Fig. 1. Their air temperature was $1290 \mathrm{~K}$, which is above the auto-ignition temperature. DNS computations of Grout et al. [1] yield some properties of a jet burning in a cross-flow that was heated to $750 \mathrm{~K}$, but their DNS was limited to very modest Reynolds numbers. Figure 2 shows their computed instantaneous flame index and their computed scalar dissipation rates. Their flames were nearly attached (their flame base was lifted by about 2 jet diameters) because their cross-flow velocity was relatively low $(55 \mathrm{~m} / \mathrm{s})$.
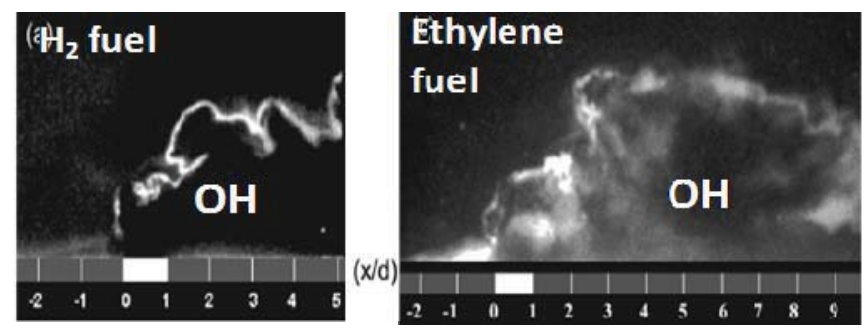

Figure 1. OH PLIF images of reaction zones of jet flame in cross flow by Ben-Yakar, Mungal and Hanson $[3,4]$. (a) hydrogen jet, (b) ethylene jet. Air static temperature $=1300 \mathrm{~K}$.
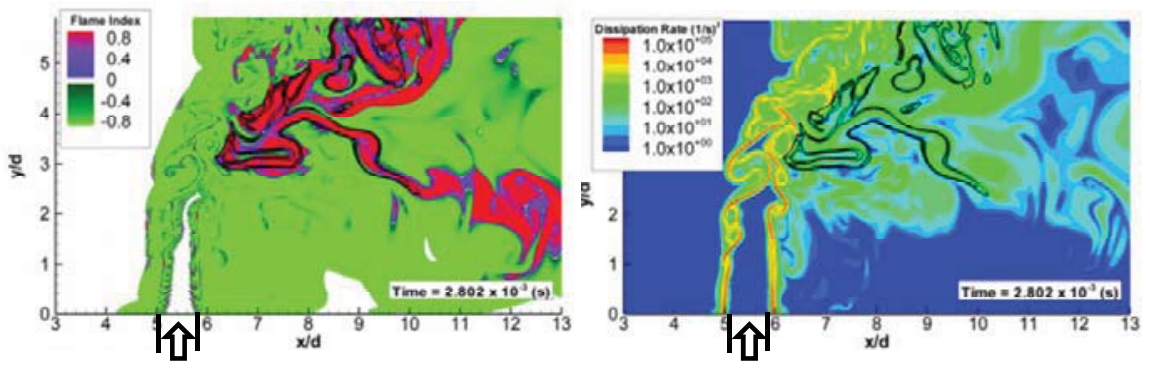

Figure 2. Computed instantaneous flame index and scalar dissipation rate, from DNS of Grout et al.[1] 
The goal of this study is to use PLIF imaging to identify the internal structure of a partiallypremixed lifted turbulent jet flame within a cross-flow of air that is heated to a temperature of $1364 \mathrm{~K}$, which is above the auto-ignition temperature. Large aerodynamic strain rates were imposed since the velocity of the cross-flow air is $480 \mathrm{~m} / \mathrm{s}$. The primary reaction zones were identified to be the layers where $\mathrm{CH}$ radicals are abundant, since $\mathrm{CH}$ is a good marker of the heat release reactions [21]. Simultaneous formaldehyde - OH PLIF was used to determine the upstream boundaries of the autoignition reactions and the primary reactions. The goal was to determine if the formaldehyde reactions begin far upstream of the primary reactions, which leads to a two-stage reaction processes.

Figure 3 is a schematic of three possible reaction zone structures. In Fig. 3a a fuel jet burns in a cold, low speed cross-flow of air. The lifted flame is known to have the structure of a triple flame at the flame base. That is, fuel and air mix but do not react in the mixing zone between the fuel jet and flame base. The center of the flame base burns as a fuel-rich premixed flame, while the far edges of the flame base are lean premixed flames, as indicated. Downstream of the center of the flame base the fuel-rich products eventually come in contact with the air stream and this creates the continuous, thin nonpremixed flame that is labeled in Fig. 3a. To model this situation, a stratified premixed flamelet approach is applicable for the flame base, while a non-premixed flamelet approach is applicable for the downstream reaction region.
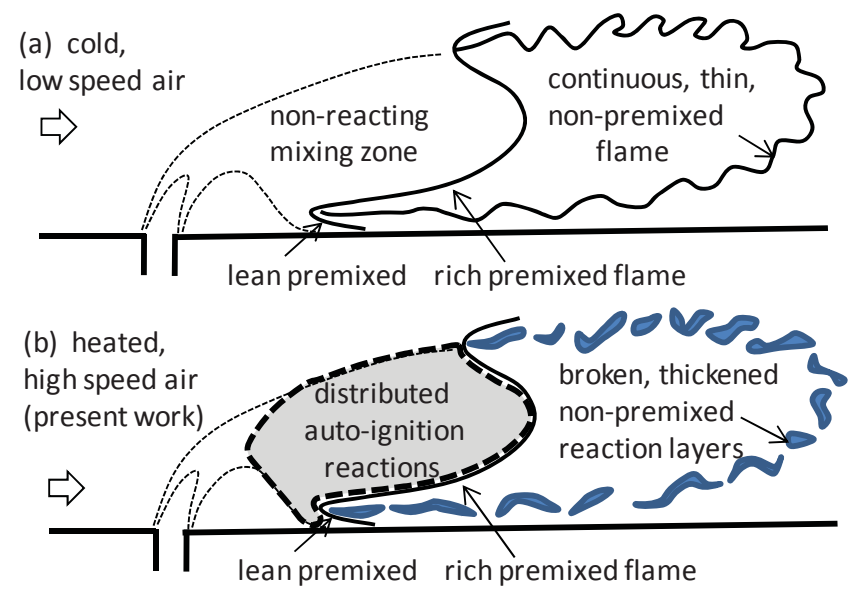

(c) co-flow, heated,

low speed air

(Cabra burner)

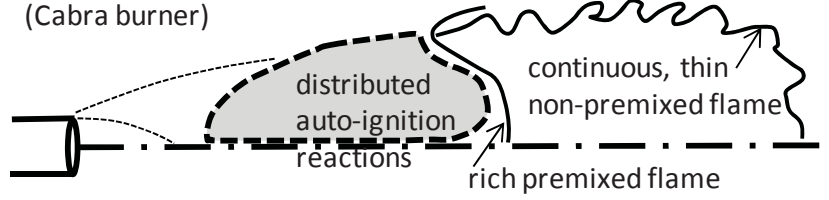

Figure 3. Schematic of highly-lifted flames, illustrating some effects of raising the air temperature above the auto-ignition temperature and increasing the air velocity (and aerodynamic strain rate). (a) cold, lower speed air case with continuous, thin non-premixed flame; (b) heated, high speed air (present work) results in distributed auto-ignition and broken, thickened flamelets, as shown below; (c) Cabra burner with heated, low speed co-flowing air [7-11].

Figure $3 b$ indicates the changes that occur when the air stream is heated to a temperature above the ignition temperature and the air velocity is made sufficiently large. This schematic is based on the images that were recorded in the present work, which are described below. Where the heated air and fuel 
mix, some auto-ignition reactions occur which create intermediates such as formaldehyde in the grey shaded region. The flame base has a triple flame structure containing both rich and lean premixed regions. At downstream locations the non-premixed flame is broken and thickened into thick layers of separated reaction zones. Modeling of the reaction zones that are shown in Fig. 3b represents a challenge. A two-zone approach [2] could simulate the auto-ignition (grey) region as a set of stratified distributed reactions, while the downstream zone would require a new model that handles broken and thickened reaction layers.

Figure 3c illustrates a Cabra burner flame [7-11]. The fuel and air are co-flowing, and the air is heated but is at a relatively low speed. Therefore auto-ignition chemistry is important, but the aerodynamic strain rates do not create the broken and shredded reaction layers seen in Fig. 3b.

\section{Experimental Arrangement}

The experiments were performed in the Michigan Supersonic Combustion Facility that is shown in Figure 4. A two dimensional Mach 2.2 nozzle is followed by a constant area section in which shock waves decelerated the air to a Mach number of 0.65 upstream of the fuel jet. The test section cross section is 25.4 $\mathrm{mm}$ by $38.1 \mathrm{~mm}$. A constant area section extends $402 \mathrm{~mm}$ upstream of the fuel jet. Room temperature gaseous fuel was injected sonically through a single $2.49 \mathrm{~mm}$ diameter port located in the test section wall. A downstream spark plug was used to ignite the jet flame. To perform PLIF imaging, fused silica windows $305 \mathrm{~mm}$ in length were mounted in three sidewalls. An electric heater and hydrogen fueled vitiated air heater were used to achieve the air stagnation temperatures of up to 1470K. Make-up oxygen was added to insure that the $\mathrm{O}_{2}$ mole fraction is 0.21 in the air stream.

The run conditions for the two cases tested are given in Table 1 . The addition of hydrogen to the ethylene fuel in Case 1 was necessary to achieve good flame stabilization. The run times were limited in

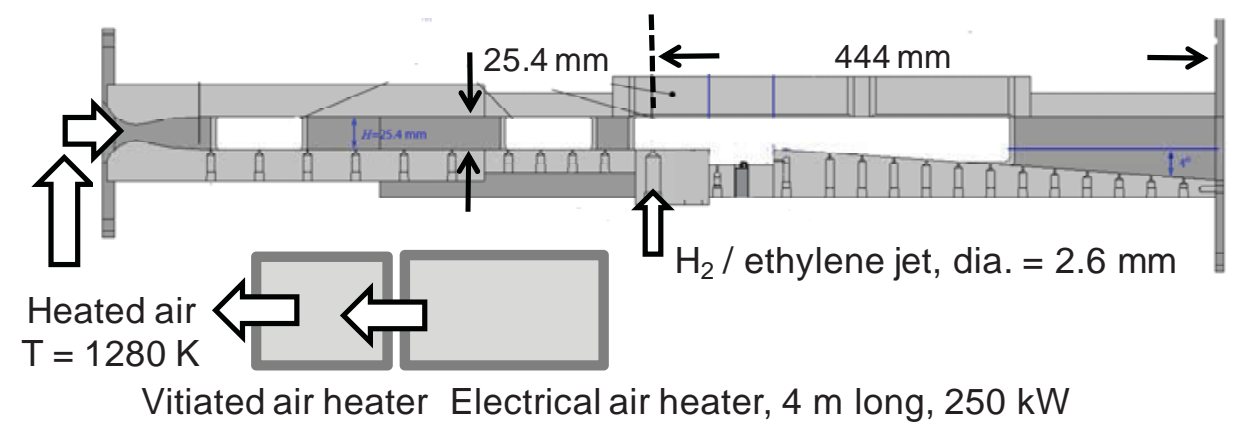

Figure 4. Michigan Reacting Jet in Heated Cross-Flow.

\begin{tabular}{|c|c|c|c|c|c|c|c|c|c|}
\hline Case & fuel by & $\mathrm{T}_{\mathrm{A}}$ air static & $T_{F}$ fuel static & $\rho_{\text {F fuel }}$ & $\rho_{\mathrm{A}}$ air & $\mathrm{U}_{\mathrm{F}}$ fuel & $\mathrm{U}_{\mathrm{A}}$ air & $\mathrm{M}_{\mathrm{A}}$ air & $q=$ \\
\hline & volume & temperature & temperature & density & density & velocity & velocity & Mach & $\left(\rho_{\mathrm{F}} \mathrm{U}_{\mathrm{F}}^{2}\right) /$ \\
\hline & & $\mathrm{K}$ & & $\mathrm{kg} / \mathrm{m}^{3}$ & $\mathrm{~kg} / \mathrm{m}^{3}$ & $\mathrm{~m} / \mathrm{s}$ & $\mathrm{m} / \mathrm{s}$ & number & $\left(\rho_{A} U_{A}^{2}\right)$ \\
\hline 1 & $50 \% \mathrm{C}_{2} \mathrm{H}_{4}, 50 \% \mathrm{H}_{2}$ & 1364 & 248 & 3.74 & 0.69 & 439 & 480 & 0.65 & 25 \\
\hline 2 & $\mathrm{H}_{2}$ & 1280 & 248 & 0.65 & 0.66 & 1207 & 465 & 0.65 & 36 \\
\hline
\end{tabular}

Table 1. Run conditions for Jet-in-Heated Cross-Flow Experiment. Fuel jet diameter $\mathrm{d}_{\mathrm{F}}=2.49 \mathrm{~mm}$. 
order to prevent thermal damage to the uncooled combustor. All the flow control and data acquisition equipment was controlled by a Labview program. For each run, the air was first heated to $450 \mathrm{~K}$ by the electric heater. The vitiator oxygen flow was then started, followed two seconds later by the spark ignited vitiator fuel. Four seconds after vitiator ignition, the spark was turned on. One second later, the main fuel injection began. The main fuel flow was maintained for three seconds before shutdown begins.

The CH PLIF system used in the study is based on the method of Carter et al. [22] The Q1(7.5) transition of the $\mathrm{B}^{2} \Sigma-\mathrm{X}^{2}(0,0)$ band of the $\mathrm{CH}$ molecule was excited by pumping at $390.30 \mathrm{~nm}$. The resulting fluorescence from the $\mathrm{A}-\mathrm{X}(1,1), \mathrm{A}-\mathrm{X}(0,0)$, and $\mathrm{B}-\mathrm{X}(0,1)$ bands was detected in the $420 \mathrm{~nm}$ to $440 \mathrm{~nm}$ range. This method gives a relatively high fluorescence yield and large separation between the excitation and fluorescence wavelengths which allows for sufficient filtering of the excitation beam. A diagram of the PLIF system arrangement is shown in Fig. 5. The second harmonic of a Nd:YAG laser (Spectra-Physics LAB-150) was used to pump a dye laser (Sirah CSTR-D-24). A mixture of Rhodamine 610 and Rhodamine 640 dyes were used to obtain a beam near $616 \mathrm{~nm}$. This beam was mixed with the $1064 \mathrm{~nm}$ beam from the Nd:YAG laser using a KD*P mixing crystal. The resulting 390.30nm beam was separated from the $616 \mathrm{~nm}$ and $1064 \mathrm{~nm}$ beams using a Pelin-Broca prism. The $390.30 \mathrm{~nm}$ beam was expanded using a 3:1 Galilean telescope and a concave cylindrical lens with a focal length of -100 mm. The central $40 \%$ of the beam was then focused into a sheet using a convex spherical lens with a focal length of $1000 \mathrm{~mm}$. The resulting sheet had a height of $60 \mathrm{~mm}$ and a thickness of 300 microns $\left(1 / \mathrm{e}^{2}\right.$ width) in the region of interest.

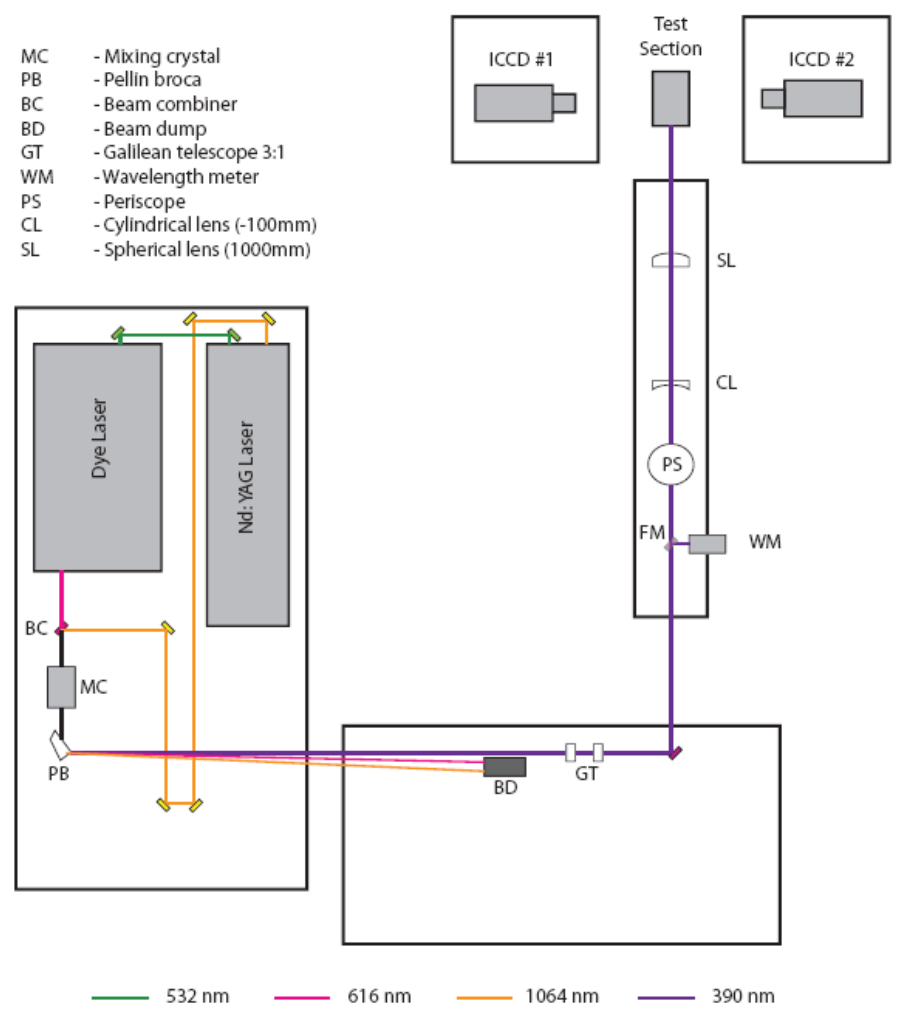

Figure 5. The CH PLIF system arrangement

The energy in the sheet was $8 \mathrm{~mJ} /$ pulse. The $9 \mathrm{~ns}$ duration of each pulse and $1 \mathrm{~cm}^{-1}$ line width of the beam gave a spectral intensity of approximately $5 \times 10^{6}\left(\mathrm{~W} / \mathrm{cm}^{2}\right) / \mathrm{cm}^{-1}$. This is five times greater than the spectral intensity needed for saturation. Saturation is therefore expected in the center of sheet width 
and the center of the pulse, but not in the edges of time or space. A 16-bit Andor Istar intensified CCD camera was used to collect the fluorescence. A band pass interference filter with a 430nm center wavelength and $10 \mathrm{~nm}$ full-width at half-maximum was used to block scattering from the pump beam and flame luminosity. A KV418 filter was also used to further block scattering from the pump beam. A f/2.0, $50 \mathrm{~mm}$ Nikkor lens with a $12 \mathrm{~mm}$ extension tube was used to obtain the desired field of view size. The CCD was binned $3 \times 3$ and cropped to obtain an array of super pixels $341 \times 214$ with each superpixel covering 220 microns.

To remove most of the interferences caused by flame luminosity from the PLIF images, a second intensified camera viewed the test section from the opposite side. It also was gated at $15 \mathrm{~ns}$ and was triggered $50 \mathrm{~ns}$ before the arrival of the laser sheet and thus recorded only flame luminosity. The flame luminosity from the second camera was subtracted from the images acquired by the first camera. Thus this correction reduces, but does not eliminate, the entire flame luminosity signal since luminosity is a line of sight measurement. To simultaneously image both the auto-ignition reaction zone and the primary reaction zone, simultaneous formaldehyde-OH PLIF diagnostics were used. The formaldehyde PLIF was excited using the $355 \mathrm{~nm}$ output from a frequency tripled Nd:YAG laser, while the OH PLIF was excited by the Nd:YAG pumped dye laser tuned to $282 \mathrm{~nm}$.

\section{Results (a) Structure of the Primary Reaction Zone (the Flame)}

The primary reaction zone was imaged in two ways: using direct chemiluminescence from $\mathrm{CH}^{*}$ and using $\mathrm{CH}$ PLIF. Figure 6 illustrates a $\mathrm{CH}^{*}$ chemiluminescence image for Case 1 conditions listed in Table 1 . The air velocity has a static temperature of $1364 \mathrm{~K}$ and a velocity of $480 \mathrm{~m} / \mathrm{s}$. Note that the $\mathrm{CH}^{*}$ chemiluminesence first occurs at $\mathrm{x} / \mathrm{d}=15$ in this lifted flame; there is no $\mathrm{CH}^{*}$ luminosity seen in the liftoff region. The $\mathrm{CH}^{*}$ luminosity extends to about $\mathrm{x} / \mathrm{d}=40$. The $\mathrm{CH}^{*}$ chemiluminescence is a line-ofsight measurement and is a good indicator of the time-averaged heat release distribution. It is not a good indicator of the internal structure of the reaction layers, so CH PLIF imaging also was performed.

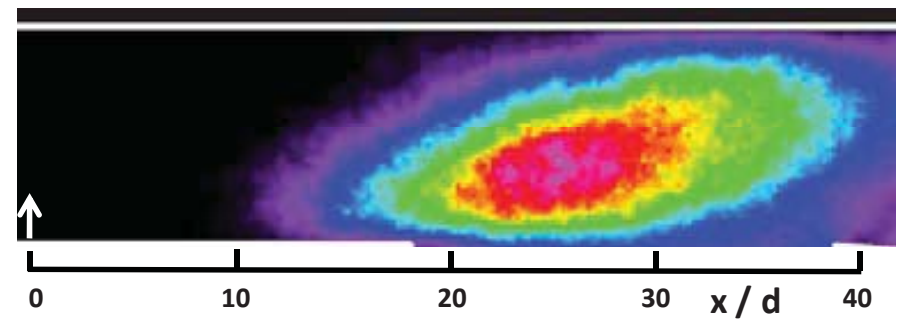

Fig. 6. Time-averaged $\mathrm{CH}^{*}$ chemiluminescence from the jet flame in a cross-flow. Case 1 , fuel $=\mathrm{H}_{2}$ $\mathrm{C}_{2} \mathrm{H}_{4}$. Note that there is no flame luminosity in the auto-ignition region $(0<\mathrm{x} / \mathrm{d}<15)$. Luminosity begins at the flame base at $\mathrm{x} / \mathrm{d}=15 . \mathrm{d}=2.49 \mathrm{~mm}$.

The structure of reaction layers determined using CH PLIF; some results appear in Fig. 7. Four regions were recorded separately and at random times, and the images are placed next to each other. The time-averaged $\mathrm{CH}$ pattern in Fig. 7a looks similar to the $\mathrm{CH}^{*}$ chemiluminescence in Fig. 6; the brightest region in Fig. 7a ends at about $\mathrm{x} / \mathrm{d}=40$, as it does in Fig. 6. However, the threshold level in Fig. 7a was set at a low level to record low levels of CH PLIF signal farther downstream.

The instantaneous structure of the downstream (non-premixed) flame is seen in Fig. 7b to be that of a set of broken (shredded) and thickened flamelets. A flamelet here is defined to be any reaction layer 
that is consistently 3-4 times longer than it is wide. Thus gradients are much larger in one direction (normal to the layer) than in the other two directions. It is not implied that the flamelet is a laminar flamelet. The $\mathrm{CH}$ is seen to be confined to thickened layers (2-3 mm thick) which are more than ten times thicker than a laminar flamelet for these conditions. Two factors that are believed to be responsible for the thickening of the $\mathrm{CH}$ layers are the high strain rates and the turbulence that may enter the reaction layers. If the air was not preheated then the highly strained flame would blow out. In fact lowering the air temperature by $200 \mathrm{~K}$ causes complete flame blowout in this experiment. Figure 7c is a schematic of the broken, thickened flamelets seen in Fig. 7b. These reaction layers form a very coherent boundary that is seen to enclose the fuel jet. The enclosed fluid is expected to consist of fuel, intermediates and products at these downstream locations. At other times, Figs. 7d and 7e illustrate that the structure is similar to that observed in Fig. 7b.
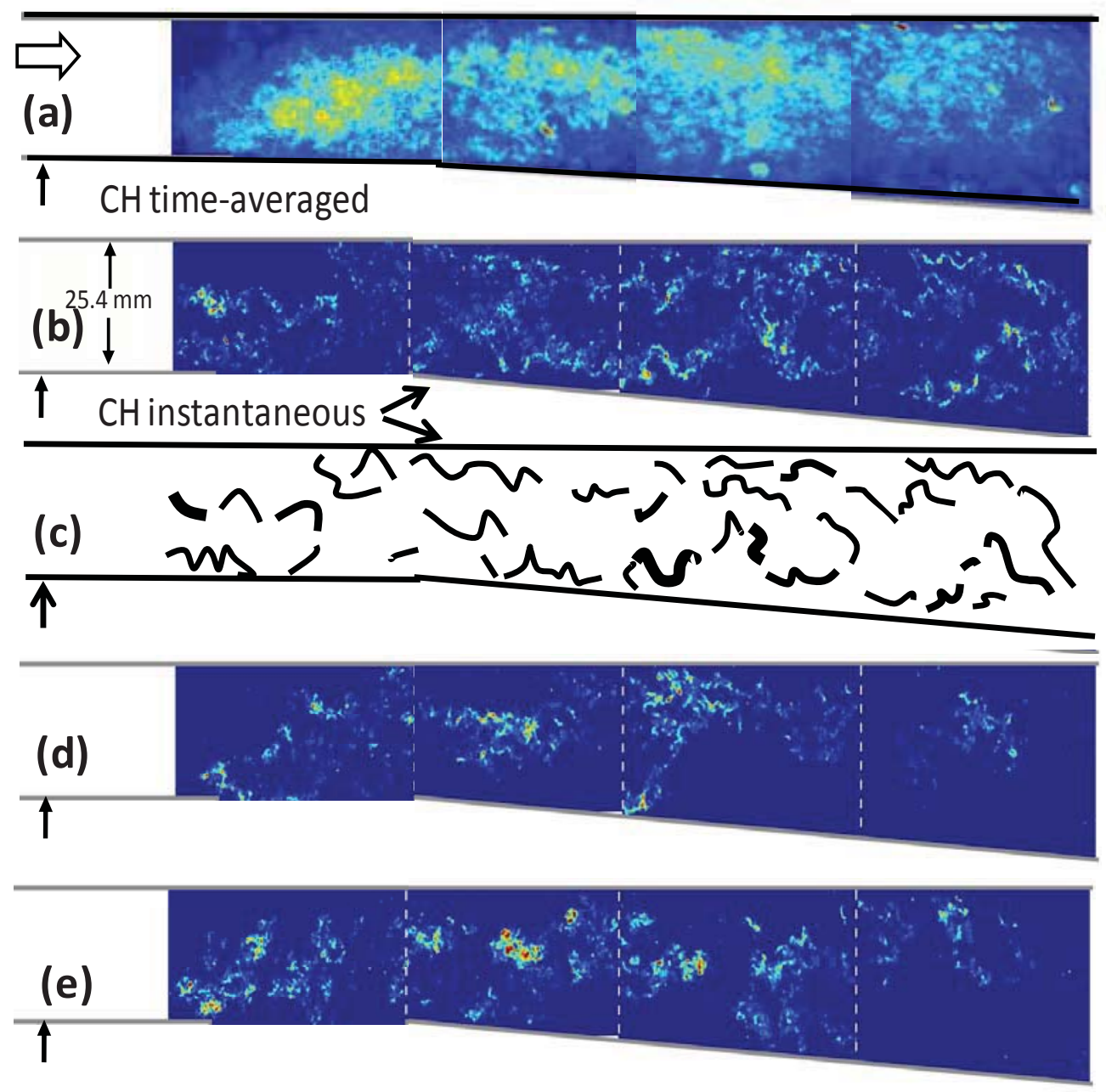

Fig. 7. Structure of the primary reaction zone (broken and thickened flamelets) in the downstream region. Case $1, \mathrm{H}_{2}-\mathrm{C}_{2} \mathrm{H}_{4}$ fuel, cross-flow air static temperature and velocity: $1364 \mathrm{~K}, 480 \mathrm{~m} / \mathrm{s}$. 


\section{Results (b) Structure of the upstream distributed auto-ignition zone}

Formaldehyde PLIF images indicates that far upstream of the $\mathrm{CH}$ reaction layer there are secondary fuel breakdown reactions that occur in fairly homogeneous distributed reaction region. The white line in Fig. 8 marks the upstream boundary of the $\mathrm{CH}_{2} \mathrm{O}$ region, while the colored zones labeled $\mathrm{OH}$ indicate the upstream boundary of the primary reactions. For clarity, the entire formaldehyde signal is not shown since only the upstream boundary is of interest. Our primary flame is denoted an "auto-ignitionassisted" flame. In the liftoff region $(0<\mathrm{x} / \mathrm{d}<15)$ there is fuel-air mixing and fuel breakdown, but no primary reactions. In this liftoff region formaldehyde PLIF signal is observed but no $\mathrm{OH}$ or $\mathrm{CH}$ or any $\mathrm{CH}^{*}$ chemiluminescence. In the primary reaction region the $\mathrm{OH}, \mathrm{CH}$ and $\mathrm{CH}^{*}$ signals are observed. While it cannot be conclusively determined from our data that the primary reaction zone consist of a triple flame followed by a non-premixed flame, the data are fully consistent with the structure shown in Fig. 3b. It is noted that the primary reactions ( $\mathrm{OH}$ boundary) is seen in Fig. 8 to start farther upstream on the lower side of the jet. The $\mathrm{OH}$ starts to occur much farther downstream on the upper side of the jet. This is because of the higher strain rates on the upper side of the jet.

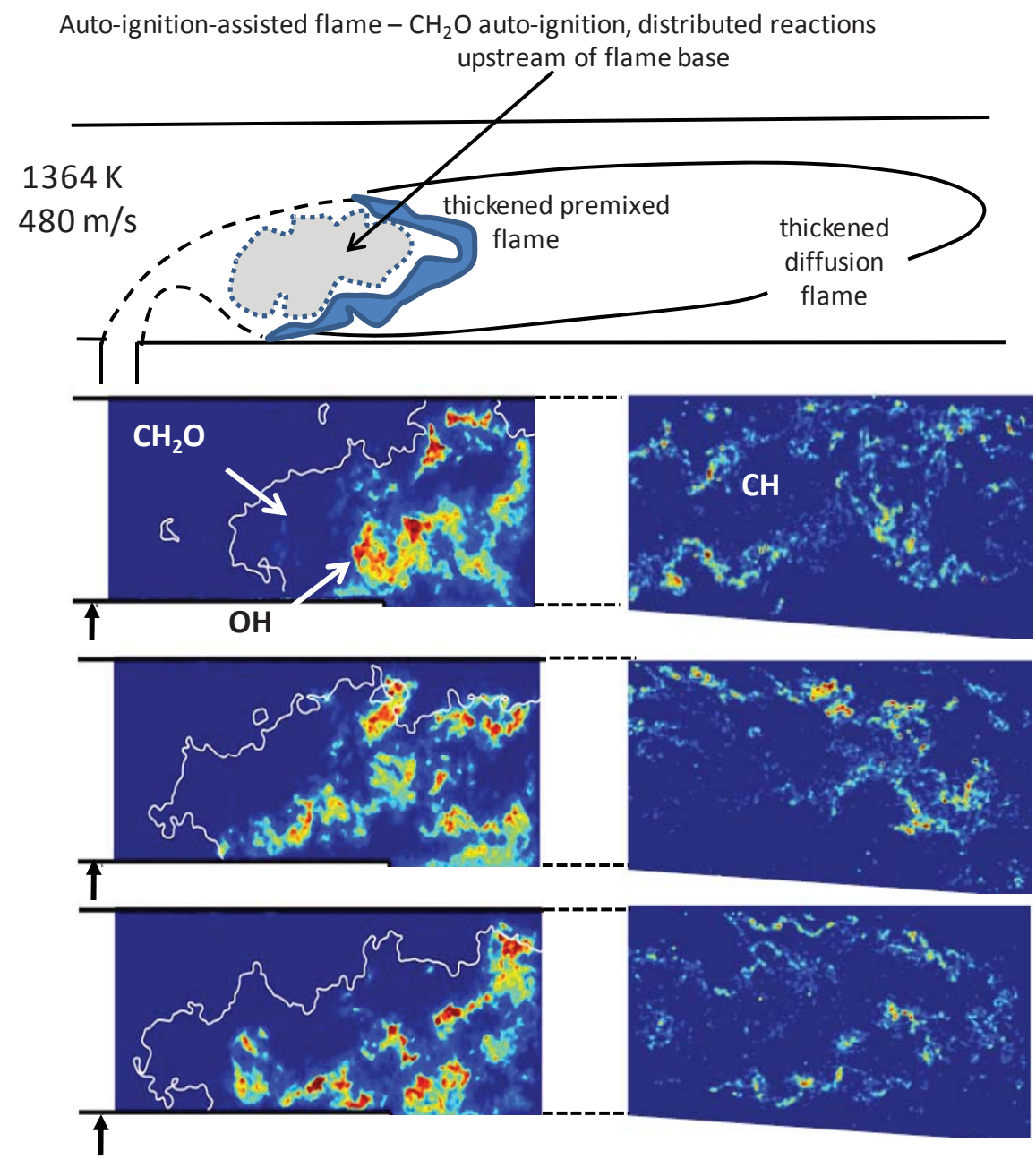

Fig. 8. Simultaneous Formaldehyde-OH PLIF images showing that broad distributed reactions (autoignition) occur upstream of the $\mathrm{OH}$ which marks the upstream boundary of the primary reaction layers (flames). Case $1, \mathrm{H}_{2}-\mathrm{C}_{2} \mathrm{H}_{4}$ fuel. 
Some cross-sectional views of the OH PLIF signal is shown in Fig. 9 at $\mathrm{x} / \mathrm{d}=16.3$. The white line is the boundary of the jet core. The inner boundary of the $\mathrm{OH}$ signal indicates where the $\mathrm{OH}$ reactions begin, which is a marker of where the primary reactions begin. It is noted that the primary reactions are confined to the lower side of the fuel jet at this location since the upper side experiences excessive aerodynamic strain, and the reactions on the upper side must begin farther downstream.

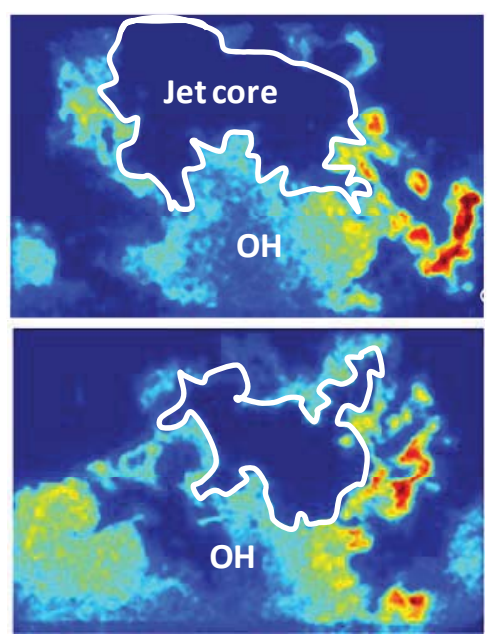

Fig. 9. Cross sectional view of the primary reaction zones at $\mathrm{x} / \mathrm{d}=16.3$, which are identified by colored regions that mark the OH PLIF signal intensity. Case $1, \mathrm{H}_{2}-\mathrm{C}_{2} \mathrm{H}_{4}$ fuel. $\mathrm{d}=2.49 \mathrm{~mm}$.

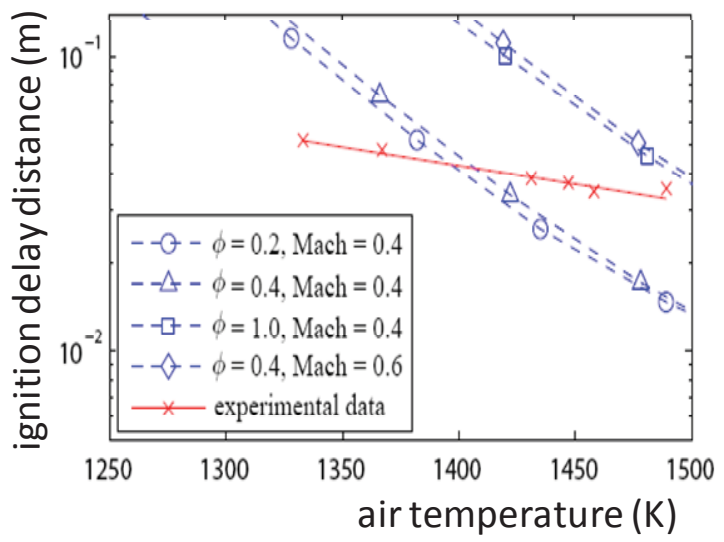

Fig 10. Auto-ignition delay distances computed for the conditions of Case 1: 50\% ethylene, 50\% hydrogen fuel reacting in air. Red line: experimentally measured delay distances. Note: the local air Mach number and fuel equivalence ratio within the jet is expected to vary from 0.4 to 0.6 and from 0.2 to 1.0 , respectively, so the computed values (blue lines) bracket the expected conditions.

The ignition delay distance was defined to be the distance from the fuel jet to the first occurrence of $\mathrm{CH}^{*}, \mathrm{CH}$ and $\mathrm{OH}$ as described above. This measured distance is plotted as the red line in Fig. 9 for various air temperatures. It was decided to compare this distance to the delay times computed using CHEMKIN for the same fuel mixture (50\% ethylene, $50 \%$ hydrogen). However, the gas velocity is not known within the jet mixing region, nor is the fuel-air equivalence ratio $(\phi)$ which varies in space. Therefore it was assumed that the gas mixture Mach number in the mixing region varied between 0.4 and 0.6 and that $\phi$ varied between 0.2 to 1.0. The resulting blue curves plotted in Fig. 10 indicate the bounds of the computed delay distances. It is seen that there is sufficient overlap between blue (computed) and 
the red (measured) delay distances to conclude that auto-ignition process is a reasonable explanation of the measured reaction zone structure.

\section{Results (c) Flame length, heat release rate and wall pressure distributions}

A useful first assessment of CFD simulations of an experiment can be achieved by comparing global quantities such as the flame length, the heat release rate distribution, and the wall pressure distribution. For the present experiment, the fuel flow rate was varied and the flame length was found to increase linearly, as shown by Fig. 11a below. This linear increase indicates that the turbulent diffusivity is not dominate by the fuel jet properties, as in a simple jet flame. Instead the mixing is highly dependent on the air flow. To generate Fig. 1a the air properties were kept constant while the flame was required to become longer in order to consume the increasing amount of fuel flow.

The heat release rate distributions also were measured for four different fuel flow rates and they are plotted in Fig. 11b. To determine the heat release rate, the images of $\mathrm{CH}^{*}$ were recorded and at each axial location the $\mathrm{CH}^{*}$ signal was integrated along the transverse direction. The resulting curve of Q(x) was normalized such that the total area under the curve equals the known total heat release rate, which is the measured fuel flow rate multiplied by its lower heating value. The flame length was defined to be the distance from the fuel port to the location where the heat release rate dropped to $10 \%$ of its maximum value. This quantity can be accurately determined from both experiments and models. It provides a useful assessment of whether or not a model correctly simulates the overall mixing and combustion processes, including the those associated with auto-ignition, premixed and non-premixed flames.
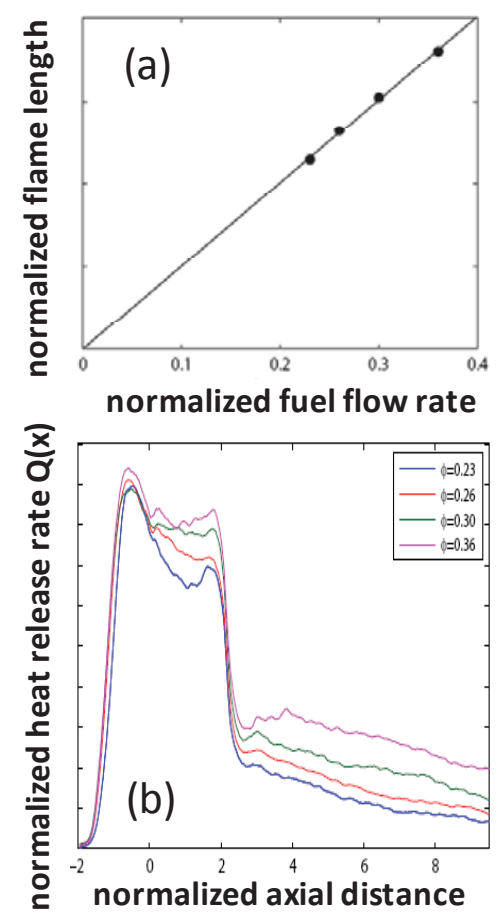

Figure 11. Measured flame lengths (a) and heat release profiles (b) for various fuel flow rates. 


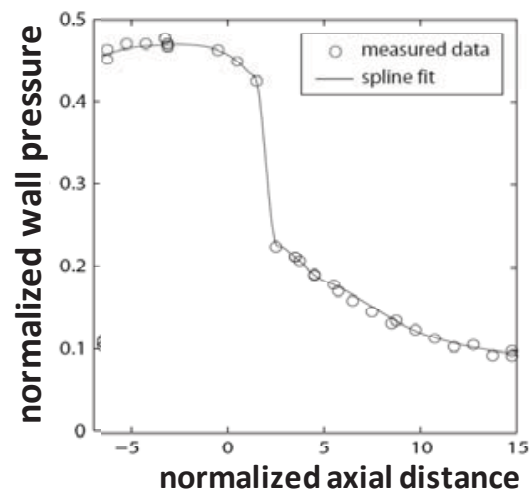

Figure 12. Measured wall pressures for Case 1.

Wall pressure was measured and was found to decrease in the flow direction in the manner shown in Fig. 12. The heat addition by the flame drives the Mach number toward one, which causes the gas velocity to increase and the wall pressure to decrease in the x-direction. The confinement of the duct walls was necessary because of the high temperature of the air flow, which had to be properly exhausted for safety reasons. The size of the confining duct was limited by the size of the air heaters. The walls can be advantageous for CFD modeling since they limit the size of the CFD domain and they provide welldefined boundary conditions.

\section{Conclusions:}

1. The structure of the combustion of a jet-in-a-cross-flow of air that is above the auto-ignition temperature was found to differ from that of a jet burning in a low temperature air cross-flow. PLIF images show that the chemistry does not occur in a pure auto-ignition process and it does not occur in a pure flame. Instead there are three distinct regions. In an upstream auto-ignition region the secondary reactions create formaldehyde in a nearly homogeneous distributed reaction zone. The primary reactions occur in two regions: the flame base has the properties of a stratified premixed flame, while the downstream reactions occur within turbulent non-premixed flames.

2. This experiment provides one of the few documented cases of highly broken (shredded) and thickened flamelets. The high strain rates causes the shredding and thickening, while the high air temperature prevents the flame from blowing out. The structure observed in three distinct regions suggests that a multi-zone model would be appropriate.

3. Heat release distribution shows three distinct regions: lifted region where there is essentially no heat release (only fuel-air mixing and fuel decomposition into formaldehyde), a flame base region where there is a very large heat release, and a downstream region of lower heat release rate that decays toward zero at the end of the flame. The measured heat release distribution is consistent with the PLIF images; the flame base region has properties of a stratified premixed flame and the downstream region is a diffusion flame. 
4. The length of the jet flame in cross-flow increases linearly with fuel flow rate, indicating that the mixing and reactions do not change significantly as the fuel flow is increased, thus a longer flame is required to consume the larger amount of fuel. Wall pressure and heat release rate distributions also were recorded for future comparisons to numerical computations.

\section{References}

1. R. W. Grout, A. Gruber, C.S. Yoo, J. H. Chen, to appear, Proc. Combust. Inst. 33 (2010).

2. D.J. Cook, H. Pitsch, J.H. Chen, E.R. Hawkes, Proc. Combust. Inst. 31 (2007) 2903-2911.

3. A. Ben-Yakar, M.G. Mungal, R.K. Hanson, Physics of Fluids 18 (2006) 026101.

4. A. Ben-Yakar, R.K. Hanson, Proc. Combust. Inst. 27 (1998) 2173-2180.

5. D. Han, M.G. Mungal, Combust. Flame 133 (2003), 1-17.

6. M. Ryan, M. Gruber, C. Carter, T. Mathur, Proc. Combust. Inst. 32 (2009) 2429-2436.

7. R. Cabra, J-Y. Chen, R.W. Dibble, A.N. Karpetis, R.S. Barlow, Combust. Flame 143 (2005) 491-506.

8. R. Cabra, T. Myrvold, J-Y. Chen, R.W. Dibble, A.N. Karpetis, R.S. Barlow, Proc. Combust. Inst. 29 (2002) 1881-1888.

9. C.N. Markides, E. Mastorakos, Proc. Combust. Inst. 30 (2005) 883-891.

10. T. Myhrvold, I.S. Ertesvag, I.R. Gran, R. Cabra, J.Y. Chen, Combust. Sci. Technol. 178, 6 (2006) 1001-1030

11. H. Wang, S.B. Pope, Combust. Theory and Modelling 12, 5, (2008) 857-882.

12. E. F. Hasselbrink Jr., M.G. Mungal, J. Fluid Mech. 443 (2001) 1-25.

13. E. F. Hasselbrink Jr., M.G. Mungal, J. Fluid Mech., 443 (2001) 27-68.

14. M.R. Gruber, A.S. Nejad, T.H. Chen, J.C. Dutton, J. Prop. Power 16, 3 (2000) 449-457.

15. K.C. Lin, M. Ryan, C. Carter, M. Gruber, C. Raffoul, J. Propulsion Power 26,3 (2010) 503-513.

16. C. Olbricht, F. Hahn, A. Sadiki, J. Janicka, Int J. Heat and Fluid Flow 28, 6 (2007)1215.

17. M. Fairweather, W.P. Jones, R.P.,Lindstedt, A.J. Marquis, Combust. Flame 84 (1991) 361-375.

18. L.L. Yuan, R.L. Street, J.H. Ferziger, J. Fluid Mech. 379 (1999) 71-104.

19. D.J. Micka, J.F. Driscoll, Proc. Combust. Inst. 32 (2009) 2397.

20. D.J. Micka, J.F. Driscoll, AIAA paper 2008-5071.

21. B.O. Ayoola, R. Balachandran, J.H. Frank, E. Mastorakos, C.F. Kaminski, Combust. Flame 2006;144:1-16.

22. C.D. Carter, J.M. Donbar, J. F. Driscoll, Applied Physics B, 66, (1998) 129-132. 